\section{Diaphragmatic function during sevoflurane anaesthesia in dogs}

Tohru Ide MD, Tetsuo Kochi MD,

Shiroh Isono MD, Tadanobu Mizuguchi MD
The effect of increasing the concentration of sevoflurane anaesthesia on diaphragmatic function was investigated in six mechanically ventilated dogs. Diaphragmatic function was assessed by measuring the transdiaphragmatic pressure ( $P$ di) generated during bilateral supramaximal stimulation of the cervical phrenic nerves at frequencies of $0.5,10,20.50$, and $100 \mathrm{~Hz}$ under quasi-isometric conditions. Measurements were performed at l, 1.5 and 2 MAC concentrations after maintaining stable conditions for one hour. The Pdi-stimulus frequency relationship was compared at each anaesthetic concentration. The sequence of changing anaesthetic depth was altered in random fashion among animals. The Pdi amplitude generated by single twitch $(0.5 \mathrm{~Hz})$ was unchanged at the three concentrations. In addition, no change in Pdi during 10, 20, $50 \mathrm{~Hz}$ stimulation was noted at any of the three levels of anaesthesia. By contrast, Pdi with $100 \mathrm{~Hz}$ stimulation during $2 \mathrm{MAC}$ sevoflurane exposure $\left(28.1 \pm 5.0 \mathrm{cmH}_{2} \mathrm{O}\right)$ decreased below $P$ di levels seen at I and $1.5 \mathrm{MAC}\left(35.3 \pm 4.3 \mathrm{CmH}_{2} \mathrm{O}\right.$ and $31.5 \pm$ $4.3 \mathrm{cmH}_{2} \mathrm{O}$, respectively) ( $\left.\mathrm{P}<0.05\right)$. From these results, we conclude that sevoflurane impairs diaphragmatic function in deep anaesthesia.

L'effect d' une augmentation de la concentration de sevofurane sur la fonction diaphragmatique a été investigué chez six chiens ventillés mécaniquement. La fonction diaphragmatique a éré évaluée en mesurant la pression trans-diaphragmatique ( $P d i)$ développée durant la stimulation supramaximale bilatérale des nerfs phréniques cervicaux à des fréquences de 0,5, 10,20,50, et $100 \mathrm{~Hz}$ durant les conditions quasi-isométriques. Les mesures ont été faites à $1,1.5$ et 2 MAC après le maintien d' une condition stable pour une heure. La relation entre la Pdi et la fréquence de la stimulation a été comparée avec chaque concentration de

\section{Key words}

ANAESTHETICS, VOLATILE: sevoflurane; MUSCLE, SKELETAL: diaphragm.

From the Department of Anaesthesiology, School of Medicine, Chiba University, Chiba 280, Japan.

Address correspondence to: $\mathrm{Dr}$. T. Ide, Department of Anaesthesiology, School of Medicine, Chiba University, 1-8-1 Inohana, Chiba 280, Japan.

Accepted for publication 21st August, 1990. l'anesthésique. La fréquence du changement de la profondeur de l'anesthésie a été altérée d'une façon randomisée parmi les animaux. L'amplitude de la Pdi générée par une stimulation de $0,5 \mathrm{~Hz}$ a été inchangée aux trois différentes concentrations. En plus, aucun changement dans la Pdi durant la stimulation à 10 , 20 et $50 \mathrm{~Hz}$ n'a été noté avec les trois niveaux de l'anesthésie. Par contre, la Pdi avec une stimulation de $100 \mathrm{~Hz}$ durant l'exposition à $2 \mathrm{MAC}$ de sevoflurane $\left(28,1 \pm 5,0 \mathrm{~cm} \mathrm{H}_{2} \mathrm{O}\right)$ a diminué en bas des niveaux de Pdi observés à l el l,5 MAC (35,3 $\pm 4,3 \mathrm{~cm} \mathrm{H}_{2} \mathrm{O}$ et $31,5 \pm 4,3 \mathrm{~cm} \mathrm{H}_{2} \mathrm{O}$, respectivement) ( $\mathrm{P}<0,05$ ). A partir de ces résultats, on conclut que le sevoflurane altère la fonction diaphragmatique lors d'une anesthésie profonde.

Volatile anaesthetics have been shown to depress skeletal muscle function in vitro. Waud and Waud demonstrated that halothane and enflurane depressed both direct and indirect twitch responses. ' Recently, the effect of volatile anaesthetics on the function of the diaphragm has been examined using in vivo preparations. For example, Clergue et al. demonstrated that halothane impaired the contractile properties of the diaphragm in spontaneously breathing dogs. ${ }^{2}$ Dureuil et al. and Veber et al. also demonstrated that halothane and isoflurane impaired the contractile properties of the diaphragm in mechanically ventilated rats. ${ }^{3,4}$

By contrast, we have demonstrated different effects of increasing doses of halothane and enflurane on diaphragmatic function in mechanically ventilated dogs; halothane had hardly any effect while increasing enflurane concentrations produced progressive decreases in the generated force. ${ }^{5}$ Sevoflurane has been shown to produce slightly greater ventilatory depression than halothane at equal anaesthetic depth. ${ }^{6}$ Moreover, no data are available regarding diaphragmatic function during sevofluranc anaesthesia. Therefore, the purpose of this study was to examine the effect of increasing sevoflurane concentrations on diaphragmatic function in intact dogs.

\section{Methods}

\section{Animal preparation}

Institutional approval for the study was obtained from the Animal Care and Use Committee of Chiba University 
School of Medicine. Six mongrel dogs weighing 11-15 $\mathrm{kg}$ were anaesthetized with $15 \mathrm{mg} \cdot \mathrm{kg}^{-1}$ thiopentone IV. The tracheas were intubated with a cuffed tracheal tube and anaesthesia was maintained with I-1.5 MAC sevoflurane. Sevoflurane was administered using a continuous flow vaporizer (Acoma, Japan). End-tidal anaesthetic concentration was determined with an anaesthetic gas monitor (Normac, Datex) calibrated for sevoflurane. The animals were placed in the supine postion and their lungs were mechanically ventilated throughout the experiment. Following tracheostomy, tracheal cannulae were placed and ventilation was adjusted to keep $\mathrm{PaCO}_{2}$ between 30 and $35 \mathrm{mmHg}$. The left femoral artery was cannulated to monitor blood pressure and to draw blood samples for measurement of arterial blood gas tensions using the IL blood gas analyzer (Instrumentation Laboratories, model 1302). The left femoral vein was also cannulated for the administration of fluids and bicarbonate to correct acidosis. Rectal temperature was continuously monitored and maintained at $37-38^{\circ} \mathrm{C}$ by a heating lamp.

Diaphragmatic function was assessed by measuring the transdiaphragmatic pressure (Pdi) defined as the difference between abdominal pressure (Pab) and pleural pressure (Ppl) which was generated during bilateral phrenic nerve stimulation. To measure Pab, a thin-walled latex balloon ( $5 \mathrm{~cm}$ length, $1.0 \mathrm{ml}$ air) was positioned in the abdominal cavity beneath the costal part of the diaphragm through a small midline abdominal incision and then the laparotomy was closed tightly in layers. Another thin-walled latex balloon $(0.4 \mathrm{ml})$ was also positioned in the middle third of the oesophagus for measuring Ppl. The abdominal balloon was connected to one side of the differential pressure transducer (Nihon Koden TP-60IT), and the oesophageal balloon was connected to the other side. The phrenic nerves were identified in the lower neck, and isolated from the surrounding tissue. A stimulating electrode was positioned on each, and the nerves were stimulated with supramaximal square-wave pulses of $0.2 \mathrm{~ms}$ duration (Nihon Koden SEN-3201). Single twitch stimulation was performed first, then 2-3 sec duration stimuation was applied at frequencies of $10,20,50$ and $100 \mathrm{~Hz}$. Measurement of Pdi was made two seconds after starting the stimulation. During $100 \mathrm{~Hz}$ stimulation, peak Pdi was measured at the three levels of anaesthesia. Stimulation was performed at each frequency at two-minute intervals, and the average value was used in the data analysis.

During stimulation, the airway was occluded at endexpiratory lung volume. Constancy of diaphragmatic geometry and muscle length during contraction was achieved by placing a closely fitting plaster cast around the abdomen and lower one-third of the rib cage. A schematic representation of the experimental design is shown in Figure 1.

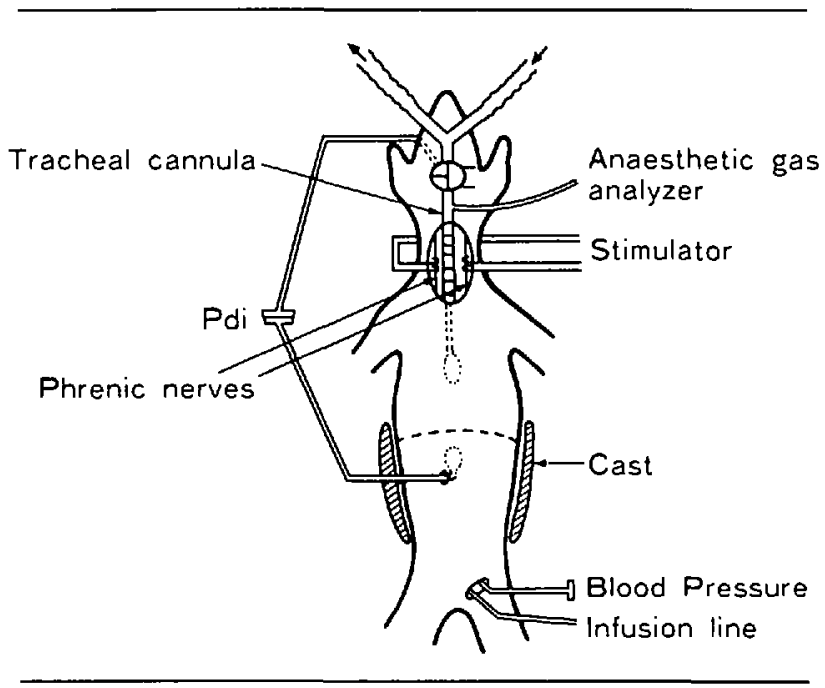

FIGURE 1 Schematic representation of animal preparation.

TABLE I Mean blood pressure (MBP), hydrogen ion concentration $\left(\left[\mathrm{H}^{+}\right]\right), \mathrm{PaCO}_{2}$ and $\mathrm{PaO}_{2}$ at three levels of sevoflurane anacsthesia

\begin{tabular}{lccll}
\hline & $\begin{array}{l}\mathrm{MBP} \\
(\mathrm{mmHg})\end{array}$ & $\begin{array}{l}\left(\mathrm{H}^{+}\right) \\
\left(\mathrm{nmol} \cdot \mathrm{L}^{-1}\right)\end{array}$ & $\begin{array}{l}\mathrm{PaCO}_{2} \\
(\mathrm{mmHg})\end{array}$ & $\begin{array}{l}\mathrm{PaO}_{2} \\
(\mathrm{mmHg})\end{array}$ \\
\hline I MAC & $111 \pm 7$ & $40.2 \pm 2.4$ & $32.1 \pm 1.2$ & $430 \pm 38$ \\
1.5 MAC & $99 \pm 6 *$ & $39.9 \pm 3.0$ & $30.7 \pm 2.0$ & $381 \pm 26$ \\
$2 \mathrm{MAC}$ & $76 \pm 4 \dagger . \ddagger$ & $38.1 \pm 1.8$ & $29.9 \pm 1.1$ & $411 \pm 36$ \\
\hline
\end{tabular}

Values are mean $\pm \mathrm{SE}$

$* P<0.05$ vs $\ \mathrm{MAC}, \dagger P<0.01$ vs $1 \mathrm{MAC}, \ddagger P<0.05$ vs $1.5 \mathrm{MAC}$

\section{Experimental protocol}

Diaphragmatic function was assessed during three levels of anaesthesia, 1, 1.5 and $2 \mathrm{MAC}$ sevoflurane, in each animal, each after one hour of steady-state conditions. The sequence of changing the anaesthetic level was randomized among animals. Arterial blood gas tensions and mean blood pressures were measured at each level of anaesthesia at the end of the run. Arterial blood pressure and Pdi were recorded on a four-channel recorder (Nihon Koden Recticorder). All values are given as mean \pm SEM. Statistical analysis was performed using analysis of variance and Tukey's test. Data were considered significantly different if $P<0.05$.

\section{Results}

Values of mean arterial blood pressure, hydrogen ion concentration $\left(\left[\mathrm{H}^{+}\right]\right), \mathrm{PaCO}_{2}$ and $\mathrm{PaO}_{2}$ during each experimental condition are summarized in Table l. Blood pressure decreased with increasing depth of anaesthesia; $\left[\mathrm{H}^{+}\right]$and blood gas tensions remained unchanged.

The effect of sevoflurane on Pdi at the three anaesthetic levels is summarized in Table II. Peak Pdi during $100 \mathrm{~Hz}$ 
TABLE II Pdi values at various stimulation frequencies of the phrenic nerve at three levels of sevoflurane anaesthesia

\begin{tabular}{|c|c|c|c|c|c|}
\hline & \multicolumn{5}{|c|}{$P d i\left(\mathrm{cmH}_{2} \mathrm{O}\right)$} \\
\hline & $0.5 \mathrm{~Hz}$ & $10 \mathrm{~Hz}$ & $20 \mathrm{~Hz}$ & $50 \mathrm{~Hz}$ & $100 \mathrm{~Hz}$ \\
\hline I MAC & $10.6 \pm 0.8$ & $12.0 \pm 1.8$ & $28.6 \pm 2.8$ & $37.3 \pm 3.5$ & $35.3 \pm 3.7$ \\
\hline $1.5 \mathrm{MAC}$ & $9.9 \pm 1.0$ & $11.8 \pm 1.9$ & $27.9 \pm 3.6$ & $32.8 \pm 4.2$ & $31.5 \pm 4.3$ \\
\hline $2 \mathrm{MAC}$ & $10.0 \pm 1.1$ & $11.4 \pm 1.5$ & $29.6 \pm 4.1$ & $35.2 \pm 5.0$ & $28.1 \pm 5.0^{*}$ \\
\hline
\end{tabular}

Values are mean $\pm \mathrm{SE}$.

$* P<0.05$ vs I MAC, 1.5 MAC.

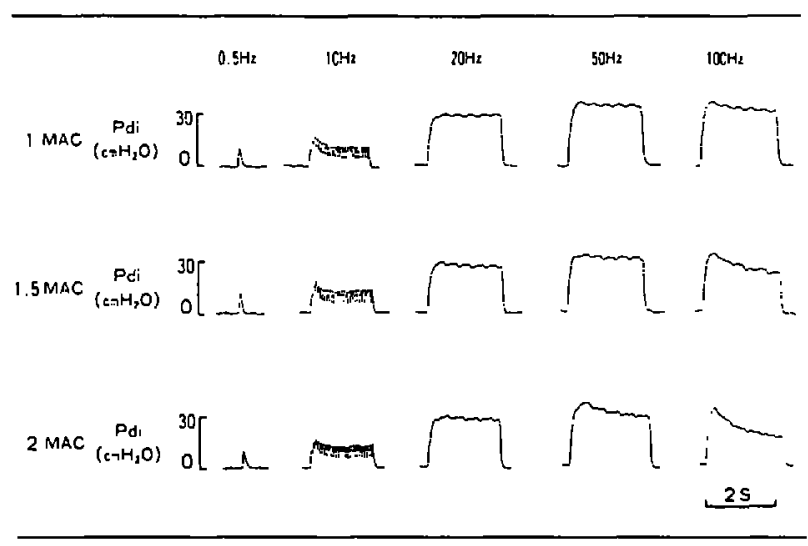

FIGURE 2 Experimental records of Pdi during sevoflurane anaesthesia at stimulating frequencies of $0.5,10,20.50$. and $100 \mathrm{~Hz}$ during 1, 1.5, 2 MAC levels of andesthesia.

stimulation at $1,1.5$ and $2 \mathrm{MAC}$ was $35.4 \pm 3.3 \mathrm{cmH}_{2} \mathrm{O}$, $34.2 \pm 3.7 \mathrm{cmH}_{2} \mathrm{O}$ and $34.9 \pm 4.0 \mathrm{cmH}_{2} \mathrm{O}$, respectively (NS). At the three levels of sevoflurane, there were no statistical differences among the values of Pdi at $0.5,10$, 20 and $50 \mathrm{~Hz}$ stimulation. During $100 \mathrm{~Hz}$ stimulation, however, a decrease $(P<0.05)$ in Pdi was observed after $2 \mathrm{MAC}$ exposure. A representive record obtained in one dog is illustrated in Figure 2. Figure 3 depicts the average force-frequency relationships at $1,1.5$ and $2 \mathrm{MAC}$ of sevoflurane. Values of Pdi were expressed as the percentage of maximum Pdi obtained in each animal.

\section{Discussion}

The main finding of this study was that, at stimulation frequencies of $0.5,10,20$ and $50 \mathrm{~Hz}$, which are considered to be the physiological range of intrinsic neural firing rates, Pdi was unchanged under any of the three concentrations of sevoflurane anaesthesia, whereas at $100 \mathrm{~Hz}$ it decreased during $2 \mathrm{MAC}$. We have previously demonstrated the effects of increasing doses of halothane and enflurane on diaphragmatic functions, and sevoflurane has an intermediate effect between these two agents.

Diaphragmatic function was assessed in this study by the force-frequency characteristics. This method has been used extensively for skeletal muscle ${ }^{7}$ and more recently in dogs, ${ }^{2,8,9}$ rats $^{4}$ and humans ${ }^{10}$ for the diaphragm. In these studies and ours, diaphragmatic function was indirectly assessed by measuring Pdi, which is a transformation of tension into pressure. Therefore the pressure generated by the diaphragm in response to electrical stimulation is affected by its length and geometry. A major determinant of the length and geometry of the diaphragm is the lung volume. Conceivably, the change of Pdi could be secondary to changes in the end-expiratory lung volume. Although an immediate decrease in functional residual capacity (FRC) after the induction of anaesthesia with barbiturates has been observed, the effect of sevoflurane on FRC has not been reported. Therefore, further changes in FRC may occur during sevoflurance exposure. In our experiment, however, the airway was occluded at endexpiratory lung volume during the measurement and its constancy was monitored by measuring the endexpiratory transpulmonary pressure. Thus changes in lung volume during the experimental procedures can be excluded. Furthermore, the cast placed around the lower one-third of the thorax and abdomen prevented deformation of the thoracoabdominal structures. The cast also ensured a constant abdominal displacement during stimulation to minimize the change in abdominal compliance which could have influenced Pdi. In this connection, it has been shown that, in the dog with a cast in place, shortening of diaphragmatic length was less than ten per cent at any frequency of stimulation and thus did not affect the tension produced by a given stimulus. " Tightness of fit of the cast may have also influenced Pdi generation by interfering with abdominal pressure and diaphragmatic length. However, this is not the case in the present experiment, as we did not observe inter-animal differences in Pdi during twitch stimulation.

During $100 \mathrm{~Hz}$ stimulation, peak Pdi at $2 \mathrm{MAC}$ sevoflurane was about the same as those at 1 and 1.5 MAC, but subsequently, pressure decreased to a substantially lower value in two seconds. Furthermore, Pdi at 20 


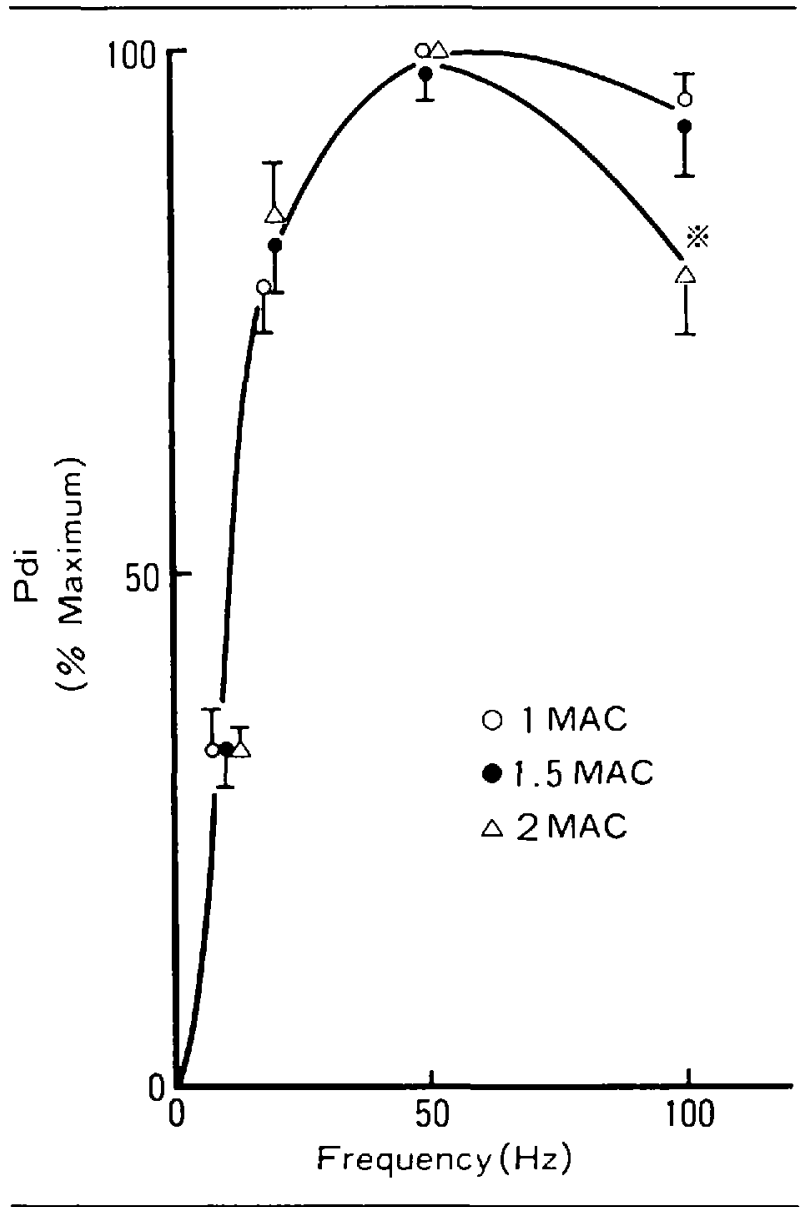

FIGURE 3 Force-frequency relationships of the diaphragm at three levels of sevoflurane anaesthesia ( $n=6 \mathrm{dogs}$ ). Each point represents average data and bars indicate I SEM. ※ represent statistical difference ( $※ P<0.05$ vs I MAC. 1.5 MAC).

$\mathrm{Hz}$ stimulation increased gradually during $2-3 \mathrm{sec}$ and did not reach peak value during stimulation. Thus we decided to measure Pdi two seconds after starting the stimulation to evaluate the fade and to standarize the measurements.

Many pathways from the brain to the contractile elements are involved in the contraction of a skeletal muscle. Our present approach of stimulating the phrenic nerve necessarily excludes the central step. Thus the changes in Pdi observed for a given stimulation during sevoflurane exposure was due to either an impairment of neuromuscular transmission and/or to an alteration of the contractile process of the diaphragm muscle. The change of the force-frequency characteristics gives some insight into the mechanism of the fatigue phenomenon. It has been suggested that selective loss of force at highfrequency stimulation indicates impairment of neuromuscular transmission ${ }^{7}$ and/or impaired membrane excitation, ${ }^{12}$ whereas selective loss of force at low-frequency stimulation is due to impairment of excitation-contraction coupling. ${ }^{13}$ If we apply this to our results, the reduction of Pdi in response to $100 \mathrm{~Hz}$ stimulation at 2 MAC sevoflurane may be due to the impairment of neuromuscular transmission and/or membrane excitation. The fact that no change of Pdi was observed at $10 \mathrm{~Hz}$ and $20 \mathrm{~Hz}$ stimulation during the three depths of anaesthesia indicates that sevoflurane does not affect excitation-contraction coupling at least at the levels of anaesthesia used in the present experiment. Furthermore, it is well known that a reduction of twitch response could be the result of reduced $\mathrm{Ca}^{++}$ release from the sarcoplasmic reticulum, decreased resting myoplasmic free $\mathrm{Ca}^{++}$concentration, or a diminished ability of the contractile proteins to respond to $\mathrm{Ca}^{++}$ activation. ${ }^{11}$ Since twitch amplitude was not altered during sevoflurane exposure, intracellular $\mathrm{Ca}^{++}$movement would not have been affected by sevoflurane anaesthesia at least in the present experimental conditions.

The reduction of Pdi in response to $100 \mathrm{~Hz}$ stimulation at 2 MAC sevoflurane may be related to a decrease in energy substrate supplies. Indeed, the ability of diaphragm to obtain adequate energy supplies to sustain contraction depends on muscle blood flow. Hussain et al. showed that blood flow to the diaphragm was autoregulated at blood pressures above $70 \mathrm{mmHg} .{ }^{14}$ Thus, in our experiment, the reduction of Pdi was not related to a decrease of blood flow since average MBP at 2 MAC sevoflurane was $76 \mathrm{mmHg}$.

It has been reported that hypercapnia and acidosis impair diaphragmatic contractility. Fitzgerald et al. have demonstrated that acidosis due to acute hypercapnia or a reduction in the bicarbonate level decreases the force of contraction of the rat diaphragm in vitro. ${ }^{15}$ Similarly, Juan et al. have observed a reduction in Pdi in anaesthetized dogs breathing carbon-dioxide. ${ }^{16}$ Thus, we adjusted ventilation to maintain $\mathrm{PaCO}_{2}$ between 30 and $35 \mathrm{mmHg}$ and administered bicarbonate to correct acidosis to exclude the possible effects of hypercapnia and acidaemia on diaphragmatic performance.

It can be concluded that sevoflurane depresses diaphragmatic function during deep anaesthesia and the mechanism may be associated with the failure of neuromuscular transmission and/or impaired membrane excitation. Further studies are needed to determine the mechanism of this impairment. The clinical importance of this phenomenon remains to be investigated in humans.

\section{Acknowledgement}

The authors wish to thank Maruishi Pharmaceutical Products (Osaka, Japan) for the generous supply of sevoflurane. 


\section{References}

1 Waud BE, Waud DR. Effects of volatile anesthetics on directly and indirectly stimulated skelctal muscle.

Anesthesiology 1979; 50: 103-10.

2 Clergue $F$, Viires $N$, Lemescle $P$, Aubier $M$, Viars $P$, Pariente $R$. Effects of halothane on diaphragmatic muscle function in pentobarbital-anesthetized dogs. Anesthesiology 1986; 64: 181-7.

3 Dureuil $R$, Viires $N$, Nivoche $Y$ et al. Different effects of halothane on diaphragm and hindlimb muscle in rats. $\mathrm{J}$ Appl Physiol 1987; 63: 1757-62.

4 Veber B, Dureuil B, Viires N, Aubier M, Pariente R, Desmonts $J M$. Effects of isoflurane on contractile properties of diaphragm. Anesthesiology 1989; 70: 684-8.

5 Kochi T, lde $T$, Isono S, Mizuguchi T, Nishino $T$. Different effects of halothane and enfluranc on diaphragmatic contractility in vivo. Ancsth Analg 1990; 70: 362-8.

6 Doi $M$, Ikeda $K$. The respiratory effects of sevoflurane. Anesth Analg 1987; 66: 241-4.

7 Edwards RHT. Physiological analysis of skeletal muscle weakness and fatigue. Clin Sci Mol Med 1978; 54: 463-70.

8 Aubier $M$, Viires $N$, Murciano D, Medrano $G$, Lecocguic $Y$, Pariente $R$. Effects and mechanism of action of terbutaline on diaphragmatic contractility and fatigue. $J$ Appl Physiol 1984; 56: 922-9.

9 Aubier M, Viires N, Murciano D, Seta JP, Pariente $R$. Effects of digoxin on diaphragmatic strength generation. J Appl Physiol 1986; 61: 1767-74.

10 Aubier M, Farkas G, De Troyer A, Mozes R, Roussos $C$. Detection of diaphragmatic fatigue in man by phrenic stimulation. J Appl Physiol 1981; 50: 538-44.

11 Howell S, Fitzgerald RS, Roussos $C$. Effects of uncompensated and compensated metabolic acidosis on canine diaphragm. J Appl Physiol 1985; 59: 1376-82.

12 Jones DA, Bigland-Ritchie B, Edwards RHT. Excitation frequency and muscle fatigue: mechanical response during voluntary stimulated contraction. Exp Neurol 1979; 64: $401-13$.

13 Edwards RHT, Hill DK, Jones DA, Merion PA. Fatigu of long duration in human skeletal muscle after exercise. J Physiol (London) 1977; 272: 769-78.

14 Hussain SNA, Roussos C, Magder S. Autoregulation of diaphragmatic blood flow in dogs. J Appl Physiol 1988; 64: 329-36.

15 Fitzgerald RS, Hauer MC, Bierkamper $G G$, Raff $H$. Responses of in vitro rat diaphragm to changes in acid-base environment. J Appl Physiol 1984; 57: 1202-10.

16 Juan G, Calverley P, Talamo C, Schnader J, Roussos $C$. Effect of carbon dioxide on diaphragmatic function in human beings. N Engl J Med 1984; 310: 874-9. 